\title{
COVID-19 vaccine development: What lessons can we learn from TB?
}

Hussain A. Safar ${ }^{1 *}$, Abu Salim Mustafa² and Timothy D. McHugh

\begin{abstract}
At the time of writing, the SARS-CoV-2 virus has infected more than 49 million people causing more than 1.2 million deaths worldwide since its emergence from Wuhan, China in December 2019. Vaccine development against SARSCoV-2 has drawn the global attention in order to stop the spread of the virus, with more than 10 vaccines being tested in phase III clinical trials, as of November 2020. However, critical to vaccine development is consideration of the immunological response elicited as well as biological features of the vaccine and both need to be evaluated thoroughly. Tuberculosis is also a major infectious respiratory disease of worldwide prevalence and the vaccine development for tuberculosis has been ongoing for decades. In this review, we highlight some of the common features, challenges and complications in tuberculosis vaccine development, which may also be relevant for, and inform, COVID-19 vaccine development.
\end{abstract}

Keywords: COVID-19, SARS-CoV-2, Tuberculosis, Vaccine

\section{COVID-19 and TB situation worldwide}

The coronavirus disease 2019 (COVID-19) and tuberculosis (TB) are among the major health problems that pose major threats to international public health, both are respiratory infections. The number of severe acute respiratory syndrome coronavirus 2 (SARS-CoV-2) infections has increased dramatically worldwide since its emergence from Wuhan, China in December 2019, with more than 49.7 million confirmed cases in 216 countries, and a worldwide average mortality rate of $2.4 \%$ at the time of writing [1], about one quarter of the world's population is infected with Mycobacterium tuberculosis, with 10 million people developing active disease and 1.5 million people dying of TB annually; making TB the leading cause of death from a single infectious agent before the emergence of SARS-CoV-2 [2, 3]. The World Health Organisation (WHO) declared the coronavirus disease COVID-19 as a pandemic in March 2020, however in 1993, TB was declared as a "global emergency" and later in 2016 the WHO developed the "Stop TB Strategy" aiming for a TB-free world in partnership with the "End TB Strategy" 2016-2035 [4]. Vaccine development is a crucial strategy for the prevention of widespread infectious diseases, reducing the morbidity and mortality rates. Long-lasting vaccines can be more cost-effective than chemotherapy and therefore can have a compelling impact on global health, as demonstrated by the successful smallpox and polio vaccines [5]. Even though there is an urgent need to develop an effective vaccine against COVID-19, the immunological and biological features of the COVID-19 vaccine must be evaluated to inform this development and introduction. TB vaccine development has been ongoing for decades exploring numerous approaches and platforms. Here we highlight some of the common features in $\mathrm{TB}$ vaccine progress that may contribute to the thinking in COVID-19 vaccine development.

*Correspondence: h.safar@ucl.ac.uk

${ }^{1}$ Centre for Clinical Microbiology, Division of Infection and Immunity,

University College London, London, UK

Full list of author information is available at the end of the article

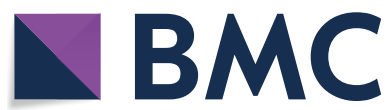

c The Author(s) 2020. This article is licensed under a Creative Commons Attribution 4.0 International License, which permits use, sharing, adaptation, distribution and reproduction in any medium or format, as long as you give appropriate credit to the original author(s) and the source, provide a link to the Creative Commons licence, and indicate if changes were made. The images or other third party material in this article are included in the article's Creative Commons licence, unless indicated otherwise in a credit line to the material. If material is not included in the article's Creative Commons licence and your intended use is not permitted by statutory regulation or exceeds the permitted use, you will need to obtain permission directly from the copyright holder. To view a copy of this licence, visit http://creativeco mmons.org/licenses/by/4.0/. The Creative Commons Public Domain Dedication waiver (http://creativecommons.org/publicdomain/ zero/1.0/) applies to the data made available in this article, unless otherwise stated in a credit line to the data. 


\section{COVID-19 mechanism of transmission and pathogenesis}

Respiratory droplets (containing SARS-CoV-2) and contact transmission are the main routes of infection for COVID-19. It is also known that infected individuals can spread the virus to other humans with viruscontaining body fluids such as sputum and saliva through the oral and nasal cavities and possibly other mucous membranes (e.g. the eyes) [3]. However, it is still unclear whether asymptomatic infected individuals can spread the infection. SARS-CoV-2 binds to human lung cells by interaction of the Spike (S) glycoprotein of the virus to its receptor, angiotensin converting enzyme 2 (ACE2), and initiates viral entry into type II pneumocytes [6]. The $S$ protein includes two domains: the S1 domain mediates binding to ACE2, and the S2 domain promotes fusion to host cell membrane [6]. The higher transmission rate of SARS-CoV-2 in comparison to other coronaviruses, such as SARS$\mathrm{CoV}$ and MERS-CoV, (3-10 fold) is believed to be a result of four amino acid changes in the $\mathrm{S1}$ domain [7]. Upon virus entry and infection of pneumocytes, viral pathogen-associated molecular patterns (PAMPs) are recognized by the host pattern recognition receptors (PRRs) which leads to local inflammatory responses and cytokine secretion such as transforming growth factor- $\beta 1$ (TGF- $\beta 1$ ), tumor necrotic factor- $\alpha$ (TNF- $\alpha$ ), interleukins $1 \beta$ and 6 (IL-1 $\beta$ and IL-6) [8]. In severe COVID-19 cases, a cytokine storm, defined as dysregulated and excessive immune responses, is associated with acute respiratory distress syndrome (ARDS) and multiple organ failure [8]. Elevated levels of IL-2, IL-6, IL-7, IL-10, IL-12, interferon- $\gamma$ (IFN- $\gamma$ ), interferoninduced protein-10 (IP-10) and TNF- $\alpha$, and lymphopenia are associated with the severity of the disease and fatal outcomes [9]. Humoral immunity plays a key role in the protection against the virus [10]. The production of neutralizing antibodies can be detected as early as four days after the infection [10]. Specific-IgM antibodies peak on the ninth day post-infection, while specific-IgG antibodies are detected after 3 weeks [10]. Cell-mediated immunity also plays an important role in mediating the immune response to SARSCoV-2 [11]. Antigen-specific $\mathrm{T}$ cells such as regulatory CD4+ T cells and CD8+ T cells, balance the battle against the virus and suppress the overproduction of cytokines that lead to aggressive inflammation [12]. In addition, CD4+helper $\mathrm{T}$ cells activate $\mathrm{T}$-dependent $B$ cells and increase the production of neutralizing antibodies; while cytotoxic CD8+ T cells kill virusinfected cells to release the virus for neutralization by antibodies [13].

\section{Challenges in vaccine development-lessons learned from TB}

Characterization of the genetic material and the antigenicity encoded by different genomic regions are important factors for vaccine development. The sequencing of $M$. tuberculosis genome and advances in comparative genomics and bioinformatics have helped to identify species-specific genomic regions and encoded proteins in different mycobacterial species $[14,15]$. By using subtractive genomic hybridization to identify genetic differences between the virulent $M$. bovis and $M$. tuberculosis, and the avirulent vaccine strain of M. bovis Bacillus Calmette-Guérin (BCG), Mahairas and colleagues, for the first time, had shown the existence of three distinct genomic regions of differences (RDs), designated as RD1 to RD3, which were found to be deleted in BCG [16]. In 1999, by using the whole genome sequence data of M. tuberculosis and comparisons with other mycobacterial species, such as M. bovis and BCG, it was shown that 16 regions of differences (RD1 to RD16) existed among $M$. tuberculosis, $M$. bovis and BCG $[17,18]$. The identification of major $M$. tuberculosis-specific antigens has provided a better understanding in the role of these antigens in inducing protective immunity against $\mathrm{TB}$ and expanded the TB vaccine development strategies (Table 1) [19].

The novel SARS-CoV-2 genome sequence is clearly less complex than that of $M$. tuberculosis and was available to the public only a few weeks after its emergence [20]. The availability of such data made it possible for scientists to develop multiple vaccine candidates targeting different areas of the virus genome [20]. The comparative genomic analysis between the coronaviruses SARS-CoV-2, SARS$\mathrm{CoV}$, MERS-CoV showed $79 \%$ and $50 \%$ sequence identity, respectively [21]. In fact, the SARS-CoV-2 showed higher genetic similarity (93.1\%) to RaTG12 virus isolated from bats, suggesting its zoonotic origin [20]. However, the most variant amino acid sequence between SARS$\mathrm{CoV}-2$ and SARS-CoV was found in the Spike (S) protein of the SARS-CoV-2 virus with similarity of $64 \%$ in the $\mathrm{S} 1$ domain and $90 \%$ in the S2 domain [22]. Furthermore, $\mathrm{Ju}$ and colleagues identified 206 monoclonal antibodies derived from B cells isolated from COVID-19 patients that bind to the viral $\mathrm{S}$ protein receptor-binding domain (RBD) [23]. These antibodies were found to be SARS$\mathrm{CoV}-2$ specific and did not cross-react with SARS-CoV and MERS-CoV [23]. This approach of identifying specific epitopes and their antigenicity is a crucial step for development of the vaccine.

In order to optimize the efficacy of vaccine formulations, adjuvants and delivery systems are often adopted. Adjuvants enhance the immunogenicity of an antigen in various ways such as (i) stabilization of the antigen 
Table 1 Pipeline of novel TB vaccines in clinical trials

\begin{tabular}{|c|c|c|c|}
\hline Vaccine name & Vaccine type & Clinical phase & Description \\
\hline Ad5 Ag85A & Adenovirus-vector & I & BCG booster-Adenovirus vector expressing Ag85A, Ag85B and TB10.4 antigens [41] \\
\hline MVA85A & Vaccinia Ankara virus-vector & I & BCG booster-Modified vaccinia Ankara virus vector expressing Ag85A [42] \\
\hline GamTBVac & Subunit vaccine & 1 & $\begin{array}{l}\text { BCG booster-Dextran-binding domain modified Ag85a and ESAT6-CFP10 MTB anti- } \\
\text { gens and CpG ODN adjuvant, formulated with dextrans [43] }\end{array}$ \\
\hline $\mathrm{AEC} / \mathrm{BCO} 2$ & Subunit vaccine & I & $\begin{array}{l}\text { BCG booster-Ag85b, ESAT6-CFP10 combined with BCG-derived CpG and aluminum } \\
\text { salt adjuvant [44] }\end{array}$ \\
\hline ID193/GLA-SE & Subunit vaccine & Ila & BCG booster-Oil in water emulsion/TRL4 agonist [45] \\
\hline MTBVAC & Live attenuated & Ila & $\begin{array}{l}\text { Live attenuated } M \text {. tuberculosis strain } \mathrm{SO} 2 \text { with mutation in phoP transcription regulator } \\
\text { gene [46] }\end{array}$ \\
\hline TB/Flu-04L & Influenza-vectored & Ila & Influenza virus strain A/Puetro Rico/8/34 H1N1 expressing Ag85A and ESAT6 [47] \\
\hline RUTI & Live attenuated & Ila & Therapeutic vaccine-purified and liposomal cellular fragments of M. tuberculosis [48] \\
\hline H56:IC31 & Subunit vaccine & $11 \mathrm{~b}$ & $\begin{array}{l}\text { BCG booster-fusion protein of Ag85B, ESAT-6 and Rv2660c formulated in IC31 adju- } \\
\text { vant [49] }\end{array}$ \\
\hline $\mathrm{M} 72 / \mathrm{ASO}_{\mathrm{E}}$ & Subunit vaccine & $\| \mathrm{b}$ & $\begin{array}{l}\text { BCG booster-fusion protein of Mtb32A and Mtb39A combined with AS01 adjuvant } \\
\text { [50] }\end{array}$ \\
\hline DAR-901 & Inactivated whole-cell & $11 \mathrm{~b}$ & BCG booster-whole cell or extract of M. obuense [51] \\
\hline VPM1002 & Live recombinant & III & $\begin{array}{l}\text { Pre and post exposure vaccine_live recombinant } M \text {. bovis expressing listeriolysin of } \\
\text { Listeria monocytogenes, lacing the urease C gene and containing hygromycin resist- } \\
\text { ance marker [52] }\end{array}$ \\
\hline MIP & Heat killed & III & Therapeutic vaccine — whole cell of extract of M. indicus pranii [53] \\
\hline M. vaccae & Heat killed & III & Therapeutic vaccine - whole cell of extract of M. vaccae [54] \\
\hline
\end{tabular}

and protection from physical and/or chemical degradation in vivo and therefore induce a potent and persistent immune response, (ii) enhancing antigen uptake, (iii) directing the antigen to specific immune cells, (iv) enhancing the stimulation of different $\mathrm{T}$ and/or $\mathrm{B}$ cells, and (v) enhancing antigen presentation [24, 25]. For TB vaccines, adjuvants and delivery systems that induce and modulate the secretion of protective Th1 immune responses, rather than pathologic Th2 and Treg immune responses, are preferred [24, 26]. The examination of chemical adjuvants, live recombinant bacteria or viruses, and DNA vaccine constructs, in combination with immunodominant TB antigens, have been shown to induce protective Th1 responses and reduce the bacterial loads in the lungs of infected mice [27-30]. There are a number of TB vaccines in the clinical trials pipeline that are being developed as primary (or replacement) vaccines or as secondary boosters to the available TB vaccine, BCG. Vaccinating healthy BCG-vaccinated adults with AERAS-402 (adenovirus expressing a fusion of $M$. tuberculosis antigens 85A, 85B, and TB10.4) and MVA85A (Modified Vaccinia Ankara expressing Ag85A) has been found to be safe, and boosted antigen-specific CD4+ and CD8+ T cell responses in phase I clinical trials [31]. Similarly, vaccinating both BCG-naïve as well as previously BCG-vaccinated adults with a human type 5 adenovirus-based vaccine expressing Ag85A (adHu5Ag85A) was shown to be safe and elicited appropriate $\mathrm{T}$ cell responses [32].

The selection of adjuvants that enhance protective immunity against SARS-CoV-2 is crucial. In contrast to $\mathrm{TB}$, neutralizing-antibodies appear to play a major role in protection against the virus [33]. This has led to the use of convalescent plasma from the COVID-19 recovery patients as a treatment strategy has had a positive impact on clinical outcome and therefore suggests a vaccine that can induce the secretion of neutralizing antibodies is ideal [33]. However, the aim of the adjuvant and delivery systems used for SARS-CoV-2 vaccines should not only be limited to antibody production but also aim to produce long-lasting immunity against the virus. Long-lived plasma cells (PC) have been shown to have a critical role in maintaining antibody levels [34]. It is still unclear whether the induction of long-lived PC is a result of vaccinating with multivalent protein antigens, type of adjuvant used, number of boosters, or an ideal combination of them all [34]. In addition, vaccination route can contribute to antibody production. This has been demonstrated for TB for which studies have shown that immunization of mice with BCGintranasally and by aerosols induced the production of IgG and IgA antibodies more than subcutaneous immunization [35].

Although BCG has been used extensively in large parts of the world and over four billion people have been 
vaccinated since the 1920 s, it has failed to show consistent protective efficacy in humans, particularly in the developing world and against adult pulmonary disease, the most common manifestation of TB [4]. Even though neonatal BCG vaccination offers protection in children up to 10-20 years, the efficacy of BCG protection against adult pulmonary TB varies from 0 to $80 \%[36,37]$. It is thought that this variation is due to different BCG preparations (and possibly different strains), exposure to certain $M$. tuberculosis strains and/or environmental mycobacteria, genetic variations among host populations, climatic and living conditions $[15,36]$. In comparison, genetic mutation and nucleotide substitution, which can lead to shifts in protein translation, are amongst the most important mechanisms of viral evolution in nature and impact on vaccine efficacy. Becerra-Flores and Cardozo reported that a mutation at position 614 of the SARS-CoV-2 spike, leading to amino acid change from aspartate to glycine, increased the virus pathogenicity and was associated with higher mortality rates globally [38]. Similarly, host genetic variation may be important, Al-Mulla and his colleagues have studied the genetic variations in ACE2, TMPRESS2, and FURIN, SARS-CoV-2 receptors in humans, in the Middle Eastern (Kuwait, Qatar and Iran) and European populations. They have concluded that the lower mortality rates in the Middle Eastern populations can be explained by the frequent deleterious variants in the FURIN gene in these populations, but not in European populations [39]. Therefore, ideally, clinical trials of vaccine candidates must be examined against different strains of the SARS-CoV-2 virus and within different populations and age groups.

\section{Current status of novel TB vaccines}

Novel TB vaccine candidates aim to either boost or replace the current available vaccine, BCG. Vaccines in development are targeting different stages of the infection/disease and different age groups. TB vaccines can be classified as (1) pre-exposure vaccines targeting individuals who have not been vaccinated with BCG, exposed to mycobacterial antigens, nor infected with TB, typically neonates, (2) post-exposure vaccines targeting individuals vaccinated with BCG, and (3) therapeutic vaccines targeting individuals infected with TB to accelerate the clearance of the pathogen (Table 1) [40].

\section{Progress in the development of vaccines against COVID-19}

To date, more than 230 COVID-19 vaccines are being developed using various technologies [55-63], some of which are "traditional" such as inactivated [62, 63], viral-vector vaccines $[58,60,61]$ and adjuvanted subunit vaccines [56]. Other vaccine technologies being developed have not been used in licensed vaccines before e.g. mRNA and DNA vaccines $[55,57,59]$. The leading vaccines in clinical trials are viral-vectored expressing the $S$ protein of the SARS-CoV-2 [58, 60, 61], mRNA vaccines $[57,59]$, inactivated and adjuvanted vaccines $[56,62,63]$ (Table 2). The aim of these vaccines is to protect from the infection and/or prevent clinical symptomatic disease and therefore reduce disease severity. At the time of writing Pfizer have reported in the media promising Phase III results for their mRNA based vaccine, but the data is not yet available.

Table 2 Pipeline of major COVID-19 vaccines in clinical trials

\begin{tabular}{|c|c|c|c|}
\hline Vaccine name & Vaccine type & Clinical phase & Description \\
\hline INO-4800 & DNA & $|/| \mid$ & Synthetic DNA vaccine targeting SARS-CoV S protein [55] \\
\hline RBD-dimer & Recombinant subunit & $\|$ & Beta-CoV vaccine against beta coronaviruses [56] \\
\hline CTII-nCoV & Adenovirus-vector & $\|$ & Adenovirus vector encodes for full-length S protein [58] \\
\hline BNT162 & mRNA & III & $\begin{array}{l}\text { Four vaccine candidates include: } \\
\text { BNT62a1 and BNT62b1: contain nucleoside modified RNA, } \\
\text { BNT162b2: uridine containing mRNA, and } \\
\text { BNT162c2: using self-amplifying mRNA. Each is composed of S protein and combined with a } \\
\text { lipid nanoparticle formulation [57] }\end{array}$ \\
\hline mRNA-1273 & mRNA & III & $\begin{array}{l}\text { Lipid nanoparticle (LNP)-encapsulated mRNA-based vaccine encoding full length S protein } \\
\text { [59] }\end{array}$ \\
\hline Ad26COVS1 & Adenovirus-vector & III & Replication deficient adenovirus type 5 vector expressing S protein [60] \\
\hline AZD1222 & Adenovirus-vector & III & Chimpanzee adenovirus vector expressing S glycoprotein [61] \\
\hline CoronaVac & Inactivated virus & III & Adsorbed COVID-19 (inactivated) vaccine [62] \\
\hline BBIBP-CorV & Inactivated virus & III & Inactivated SARS-CoV-2 HB02 strain [63] \\
\hline
\end{tabular}




\section{BCG as a vaccine for COVID-19?}

After the introduction of BCG in the 1920s, epidemiological studies have demonstrated that BCG vaccination not only protected against childhood TB, but also had an impact in reducing childhood mortality independently of TB protection [64]. Studies have suggested prophylactic effects of BCG in bacterial and viral infections as well as therapeutic effects in human papillomavirus (HPV) infection and non-invasive bladder cancer [65-67]. The prophylactic and therapeutic effects of BCG may be due to the induction of 'trained' immunity by BCG vaccination that protects against unrelated or nonspecific infections [68]. BCG vaccination induces the innate immune cells memory by activating natural killer cells, monocytes, and macrophages and by releasing pro-inflammatory cytokines IL-1 $\beta$ (TGF- $\beta 1$ ), TNF- $\alpha[68,69]$. In addition, BCG vaccination induces the secretion of various lymphocyte responses which involve the activation of CD4+ and CD8+ memory cells and modulation of Th1 and Th17 responses to non-specific infections [69].

Several ecological studies have observed the relationship between BCG vaccination and COVID-19 and they showed that COVID-19 incidence and/or mortality rates are significantly lower in the countries with universal BCG vaccination policies (e.g. China, Japan, Peru, Chile, Bangladesh) compared to countries without BCG vaccination policies (e.g. Argentina, Spain, Italy, United States) [70, 71]. It is proposed that the low incidence and/or mortality rates in these counties may, in part, be due to the protective role of BCG against viruses and to the fact that there is a degree of homology between amino acid sequences expressed by some BCG strains and SARS-CoV-2 [72]. However, although these findings are very interesting, such comparisons should be treated with caution. National lockdown measurements, population age median and health complications, and other aspects contribute to COVID-19 incidence and mortality rates. In addition, the duration of BCG protection in humans is subject to debate and there is not enough evidence to how long this protection lasts [73]. Therefore, randomised controlled trials are needed to determine the protective role of BCG vaccination against COVID19. There are several clinical trials exploring the effect of BCG vaccination on COVID-19 [74].

\section{Possible complications of COVID-19 vaccines}

Vaccine safety is crucial in the vaccine development process. A number of health and safety issues can arise from vaccination that can vary from mild fever to death. Even though live attenuated vaccines mount a natural infection and can induce a primary immune response better than inactivated whole-cell and adjuvanted vaccines, there are safety concerns when vaccinating with live attenuated pathogens. This is illustrated by immunization of children with BCG which may lead to various complications such as BCG lymphadenitis, injection site complications, and disseminated BCG disease [75]. In addition, BCG vaccination can cause disseminated BCGosis in immunocompromised individuals, e.g. HIV infected children, and therefore BCG is not approved as a vaccine for HIVexposed neonates in numerous countries [40,76]. The impaired T-cell responses in HIV-infected children, low BCG-induced CD8 $\mathrm{T}$ cell responses, IFN- $\gamma$, TNF- $\alpha$ and IL-2 cytokines secretion, and expression of "low quality" $\mathrm{T}$ cell responses, may explain the low protection provided by BCG and the dissemination of BCGosis [77].

Viral-vectored vaccines expressing bacterial/virus specific antigens are considered safer than live attenuated vaccines. However, preexisting antibodies to the viral vector and inadequate human immune response in response to the vectored vaccines are the main limitations. In phase I clinical trials of TB vaccination, the immune response to the TB Ad5 Ag85A vaccine candidate was correlated with preexisting anti-adenovirus antibodies [32]. This limitation may be resolved by changing the route of immunization. Satti and colleagues reported that aerosol administration of $\mathrm{TB}$ vaccine candidate MVA85A in humans overcame preexisting antibodies against the vaccine vector, whereas serum antibodies for the viral vector were detected after intradermal administration [78]. In addition, development of modified adenovirus vaccines, such as chimpanzee adenovirus-vectors that can induce cellular and humoral cell responses may be another option [79]. Inadequate immune responses generated by inactivated viral vaccines and/or viralvectored vaccines can cause an adverse reaction known as antibody-dependent enhancement (ADE) [70]. In ADE, viral entry into host cells is enhanced by efficiency of virus-antibody complex to FcR bearing cells. This is often noticed when the vaccine-induced antibody fails to neutralize the virus because of diluted antibody levels or inaccurate specificity [80]. This can lead to macrophage activation and inflammatory cytokine secretion and subsequently tissue damage [80]. Yip et al. showed that human macrophages were infected by SARS-CoV as a succeeding Ig-G mediated ADE [81]. Additionally, vaccinating with SARS-CoV vaccine candidate expressing spike protein induced the infection human B cells in vitro [82]. The mechanism required to develop a vaccine that mimics the natural infection and induces adequate immune responses remains an ambitious immunological approach. The immunological and serological specifications that can explain the correlation of protection against SARS-CoV-2 infection, especially neutralizing antibody titer, need to be explored. 


\section{Conclusion}

Vaccines are important tools to control and eradicate the infectious diseases. The recent SARS-CoV-2 pandemic has overwhelmed the world as there are no vaccines or effective anti-viral agents currently available to control the disease. The vaccines against SARS-CoV-2 are expected to induce both neutralizing antibodies and cellular immunity. The process of identifying appropriate antigens and delivery systems for SARA-CoV-2 vaccine is ongoing and candidate vaccines are being evaluated in experimental animal models and human clinical trials. However, the development of vaccines can be cumbersome and time-consuming as shown by the development pathway for TB. We propose that as a respiratory infection, albeit a bacterium, with a wide spectrum of host susceptibility, TB provides a useful model for COVID-19 vaccine development from which lessons can be learnt.

\section{Acknowledgements}

Not applicable.

\section{Authors' contributions}

Writing original draft: HAS. Writing-review and editing: ASM, TDM. All authors read and approved the final manuscript.

\section{Funding}

This work was funded internally with UCL Centre for Clinical Microbiology budgets and funding was independent of the study design and delivery.

\section{Availability of data and material}

Not applicable.

\section{Ethics approval and consent to participate}

Not applicable.

\section{Consent for publication}

Not applicable.

\section{Competing interests}

The authors declare no competing interests.

\section{Author details \\ ${ }^{1}$ Centre for Clinical Microbiology, Division of Infection and Immunity, Uni- versity College London, London, UK. ${ }^{2}$ Department of Microbiology, Faculty of Medicine, Kuwait University, Kuwait City, Kuwait.}

Received: 1 October 2020 Accepted: 19 November 2020

Published online: 30 November 2020

\section{References}

1. Coronavirus. Who.int. 2020. https://www.who.int/emergencies/diseases/ novel-coronavirus-2019. Accessed 12 Nov 2020.

2. Furin J, Cox J, Pai M. Tuberculosis. Lancet. 2019;393(10181):1642-56.

3. Shi Y, Wang G, Cai X, Deng J, Zheng L, Zhu H, et al. An overview of COVID19. J Zhejiang Univ Sci B. 2020;21(5):343-60.

4. Tuberculosis (TB). Who.int. 2020. https://www.who.int/news-room/factsheets/detail/tuberculosis. Accessed 22 June 2020.

5. Greenwood B. The contribution of vaccination to global health: past, present and future. Phil Trans Royal Soc B. 2014;369(1645):20130433.

6. Huang $Q$, Herrmann A. Fast assessment of human receptor-binding capability of 2019 novel coronavirus (2019-nCoV). bioRxiv. 2020.
7. Zhou P, Yang X, Wang X, Hu B, Zhang L, Zhang W, et al. A pneumonia outbreak associated with a new coronavirus of probable bat origin. Nature. 2020:579(7798):270-3.

8. Huang C, Wang Y, Li X, Ren L, Zhao J, Hu Y, et al. Clinical features of patients infected with 2019 novel coronavirus in Wuhan, China. Lancet. 2020;395(10223):497-506.

9. Wang J, Jiang M, Chen X, Montaner L. Cytokine storm and leukocyte changes in mild versus severe SARS-CoV-2 infection: review of 3939 COVID-19 patients in China and emerging pathogenesis and therapy concepts. J Leukoc Biol. 2020;108(1):17-41.

10. Li Z, Yi Y, Luo X, Xiong N, Liu Y, Li S, et al. Development and Clinical Application of A Rapid IgM-lgG Combined Antibody Test for SARS-CoV-2 Infection Diagnosis. J Med Virol. 2020;92(9):1518-24.

11. Tay M, Poh C, Rénia L, MacAry P, Ng L. The trinity of COVID-19: immunity, inflammation and intervention. Nat Rev Immunol. 2020;20(6):363-74.

12. Cecere T, Todd S, LeRoith T. Regulatory T cells in arterivirus and coronavirus infections: do they protect against disease or enhance it? Viruses. 2012:4(5):833-46.

13. Li G, Fan Y, Lai Y, Han T, Li Z, Zhou P, et al. Coronavirus infections and immune responses. J Med Virol. 2020;92(4):424-32.

14. Cole S, Brosch R, Parkhill J, Garnier T, Churcher C, Harris D. Deciphering the biology of Mycobacterium tuberculosis antigens as correlates of infection, disease, immunity and targets for vaccination. Semin Immunol. 1998;:1044-5323(18):30004-6.

15. Mustafa A. Diagnostic and vaccine potentials of ESAT- 6 family proteins encoded by $M$. tuberculosis genomic regions absent in M. bovis BCG. J Mycobac Dis. 2013;3:2.

16. Mahairas G, Sabo P, Hickey M, Singh D, Stover C. Molecular analysis of genetic differences between Mycobacterium bovis BCG and virulent $M$. bovis. J Bacteriol. 1996;178(5):1274-82.

17. Behr M, Wilson M, Gill W, Salamon H, Schoolnik G, Rane S, et al. Comparative genomics of BCG vaccines by whole-genome DNA microarray. Science. 1999:284(5419):1520-3.

18. Gordon S, Brosch R, Billault A, Garnier T, Eiglmeier K, Cole S. Identification of variable regions in the genomes of tubercle bacilli using bacterial artificial chromosome arrays. Mol Microbiol. 1999;32(3):643-55.

19. Niki M, Suzukawa M, Akashi S, Nagai H, Ohta K, Inoue M, et al. Evaluation of humoral immunity to Mycobacterium tuberculosis-specific antigens for correlation with clinical status and effective vaccine development. J Immunol Res. 2015;2015:1-13.

20. Chan J, Kok K, Zhu Z, Chu H, To K, Yuan S, et al. Genomic characterization of the 2019 novel human-pathogenic coronavirus isolated from a patient with atypical pneumonia after visiting Wuhan. Emerg Microbes Infect. 2020;9(1):221-36.

21. Lu R, Zhao X, Li J, Niu P, Yang B, Wu H, et al. Genomic characterisation and epidemiology of 2019 novel coronavirus: implications for virus origins and receptor binding. Lancet. 2020;395(10224):565-74.

22. Jaimes J, André N, Millet J, Whittaker G. Structural modeling of 2019-novel coronavirus ( $\mathrm{nCoV}$ ) spike protein reveals a proteolytically-sensitive activation loop as a distinguishing feature compared to SARS-CoV and related SARS-like coronaviruses. bioRxiv. 2020

23. Ju B, Zhang Q, Ge J, Wang R, Sun J, Ge X, et al. Human neutralizing antibodies elicited by SARS-CoV-2 infection. Nature. 2020;584:115-9.

24. Agger E. Novel adjuvant formulations for delivery of anti-tuberculosis vaccine candidates. Adv Drug Deliv Rev. 2016;102:73-82.

25. Moliva J, Turner J, Torrelles J. Immune responses to Bacillus CalmetteGuérin vaccination: why do they fail to protect against Mycobacterium tuberculosis? Front Immunol. 2017;8:407.

26. Safar H, Mustafa A, Amoudy A, El-Hashim A. The effect of adjuvants and delivery systems on Th1, Th2, Th17 and Treg cytokine responses in mice immunized with Mycobacterium tuberculosis-specific proteins. PLoS ONE. 2020;15(2):e0228381.

27. Kadir N, Sarmiento M, Acosta A, Norazmi M. Cellular and humoral immunogenicity of recombinant Mycobacterium smegmatis expressing Ag85B epitopes in mice. Int J Mycobacteriol. 2016;5(1):7-13.

28. Xiang Z, Sun R, Lin C, Chen F, Mai J, Liu Y, et al. Immunogenicity and protective efficacy of a fusion protein tuberculosis vaccine combining five Esx family proteins. Front Cell Infect Microbiol. 2017;7:226.

29. Liang Y, Zhao Y, Bai X, Xiao L, Yang Y, Zhang J, et al. Immunotherapeutic effects of Mycobacterium tuberculosis rv3407 DNA vaccine in mice. Autoimmunity. 2018;51(8):417-22. 
30. Stylianou E, Harrington-Kandt R, Beglov J, Bull N, Pinpathomrat N, Swarbrick $\mathrm{G}$, et al. Identification and evaluation of novel protective antigens for the development of a candidate tuberculosis subunit vaccine. Infect Immun. 2018:86(7):e00014-8.

31. Hokey D, O'Dee D, Graves A, Douoguih M, Pau M, Versteege I et al. Heterologous prime-boost with Ad35/AERAS-402 and MVA85A elicits potent CD8 + T cell immune responses in a phase I clinical trial (VAC7P.969). J Immunol. 2014;192 (1 Supplement)(141.14).

32. Smaill $F$, Jeyanathan M, Smieja M, Medina M, Thanthrige-Don N, Zganiacz $A$, et al. A human type 5 adenovirus-based tuberculosis vaccine induces robust $T$ cell responses in humans despite preexisting anti-adenovirus immunity. Sci Transl Med. 2013;5(205):205ra134.

33. Duan K, Liu B, Li C, Zhang H, Yu T, Qu J, et al. Effectiveness of convalescent plasma therapy in severe COVID-19 patients. Proc Natl Acad Sci USA. 2020;117(17):9490-6.

34. Slifka M, Amanna I. Role of multivalency and antigenic threshold in generating protective antibody responses. Font Immunol. 2019;10:956.

35. Tanner R, Villarreal-Ramos B, Vordermeier H, McShane $H$. The humoral immune response to BCG vaccination. Front Immunol. 2019;10:1317.

36. Fine P. Variation in protection by BCG: implications of and for heterologous immunity. Lancet. 1995;346(8986):1339-45.

37. Andersen P, Doherty T. The success and failure of BCG - implications for a novel tuberculosis vaccine. Nat Rev Microbiol. 2005;3(8):656-62.

38. Becerra-Flores M, Cardozo T. SARS-CoV-2 viral spike G614 mutation exhibits higher case fatality rate. Int J Clin Pract. 2020;74(8):e13525.

39. Al-Mulla F, Mohammad A, Al Madhoun A, Haddad D, Ali H, Eaaswarkhanth $M$ et al. A comprehensive germline variant and expression analyses of ACE2, TMPRSS2 and SARS-CoV-2 activator FURIN genes from the Middle East: Combating SARS-CoV-2 with precision medicine. bioRxiv. 2020

40. Kaufmann S, Weiner J, von Reyn C. Novel approaches to tuberculosis vaccine development. Int J Infect Dis. 2017:56:263-7.

41. A Study to evaluate safety and immunogenicity of AERAS-402-full text view-ClinicalTrials.gov. Clinicaltrials.gov. 2020. https://clinicaltrials.gov/ ct2/show/NCT01378312. Accessed 19 June 2020

42. Nemes E, Hesseling A, Tameris M, Mauff K, Downing K, Mulenga $H$, et al Safety and immunogenicity of newborn MVA85A vaccination and selec tive, delayed Bacille Calmette-Guerin for infants of human immunodeficiency virus-infected mothers: a phase 2 randomized, Controlled Trial. Clin Infect Dis. 2017;66(4):554-63.

43. Vasina D, Kleymenov D, Manuylov V, Mazunina E, Koptev E, Tukhovskaya E, et al. First-in-human trials of GamTBvac, a recombinant subunit tuberculosis vaccine candidate: safety and immunogenicity assessment. Vaccines. 2019;7(4):166.

44. Lu J, Chen B, Wang G, Fu L, Shen X, Su C, et al. Recombinant tuberculosis vaccine $A E C / B C 02$ induces antigen-specific cellular responses in mice and protects guinea pigs in a model of latent infection. J Microbiol Immunol Infect. 2015:48(6):597-603.

45. Coler R, Day T, Ellis R, Piazza F, Beckmann A, Vergara J, et al. The TLR-4 agonist adjuvant, GLA-SE, improves magnitude and quality of immune responses elicited by the ID93 tuberculosis vaccine: first-in-human trial. NPJ Vaccines. 2018;3(1):1-9.

46. Tameris M, Mearns H, Penn-Nicholson A, Gregg Y, Bilek N, Mabwe S, et al. Live-attenuated Mycobacterium tuberculosis vaccine MTBVAC versus BCG in adults and neonates: a randomised controlled, double-blind doseescalation trial. Lancet Respir Med. 2019;7(9):757-70.

47. Reactogenicity, Safety and Immunogenicity of a TB/FLU-04L Tuberculosis Vaccine-full text view-ClinicalTrials.gov [Internet]. Clinicaltrials.gov. 2020. https://clinicaltrials.gov/ct2/show/NCT02501421. Accessed 19 June 2020

48. Safety of RUTI ${ }^{\circledR}$ Vaccination in MDR-TB Patients-Full text view-ClinicalTrials.gov [Internet]. Clinicaltrials.gov. 2020. https:/clinicaltrials.gov/ct2/ show/NCT02711735. Accessed 19 June 2020

49. Suliman S, Luabeya A, Geldenhuys H, Tameris M, Hoff S, Shi Z, et al. Dose optimization of H56:IC31 vaccine for tuberculosis-endemic populations. A double-blind, placebo-controlled, dose-selection trial. Am J Respir Crit Care Med. 2019;199(2):220-31.

50. Van Der Meeren O, Hatherill M, Nduba V, Wilkinson R, Muyoyeta M, Van Brakel $E$, et al. Phase $2 b$ controlled trial of M72/AS01E vaccine to prevent tuberculosis. N Engl J Med. 2018;379(17):1621-34.

51. Masonou T, Hokey D, Lahey T, Halliday A, Berrocal-Almanza L, Wieland Alter W, et al. CD4+T cell cytokine responses to the DAR-901 booster vaccine in BCG-primed adults: a randomized, placebo-controlled trial. PLOS ONE. 2019;14(5):e0217091.

52. Loxton A, Knaul J, Grode L, Gutschmidt A, Meller C, Eisele B, et al. Safety and Immunogenicity of the recombinant Mycobacterium bovis BCG VaCcine VPM1002 in HIV-Unexposed Newborn Infants in South Africa. Clin Vaccine Immunol. 2016;24(2):e00439.

53. Sharma S, Katoch K, Sarin R, Balambal R, Kumar Jain N, Patel N, et al. Efficacy and Safety of Mycobacterium indicus pranii as an adjunct therapy in Category II pulmonary tuberculosis in a randomized trial. Sci Rep. 2017;7(1):1-2.

54. Bourinbaiar A, Batbold U, Efremenko Y, Sanjagdorj M, Butov D, Damdinpurev N, et al. Phase III, placebo-controlled, randomized, double-blind trial of tableted, therapeutic TB vaccine (V7) containing heat-killed $M$. vaccae administered daily for one month. J Clin Tuberc Other Mycobact Dis. 2020;18:100141.

55. Smith T, Patel A, Ramos S, Elwood D, Zhu X, Yan J, et al. Immunogenicity of a DNA vaccine candidate for COVID-19. Nat Commun. 2020;11(1):1-3

56. Clinical Study of Recombinant Novel Coronavirus Vaccine-ClinicalTrials. gov [Internet]. Clinicaltrials.gov. 2020. https://clinicaltrials.gov/ct2/show/ NCT04466085. Accessed 26 Aug 2020.

57. Study to Describe the Safety, Tolerability, Immunogenicity, and Potential Efficacy of RNA Vaccine Candidates Against COVID-19 in Healthy AdultsFull Text View-ClinicalTrials.gov. Clinicaltrials.gov. 2020. https://clinicaltr ials.gov/ct2/show/NCT04368728. Accessed 26 Aug 2020.

58. A Phase II Clinical Trial to Evaluate the Recombinant Vaccine for COVID-19 (Adenovirus Vector) (CTII-nCoV) - ClinicalTrials.gov. 2020. https:/clinicaltr ials.gov/ct2/show/NCT04341389. Accessed 26 Aug 2020.

59. A Study to Evaluate Efficacy, Safety, and Immunogenicity of mRNA-1273 Vaccine in Adults Aged 18 Years and Older to Prevent COVID-19-ClinicalTrials.gov. Clinicaltrials.gov. 2020. https://clinicaltrials.gov/ct2/show/ NCT04470427. Accessed 26 Aug 2020.

60. A Study of Ad26.COV2.S for the Prevention of SARS-CoV-2-Mediated COVID-19 in Adult Participants (ENSEMBLE). - ClinicalTrials.gov. Clinicaltrials.gov. 2020. https://clinicaltrials.gov/ct2/show/NCT04505722. Accessed 26 Aug 2020.

61. A phase III study to investigate a vaccine against COVID-19. ISRCTN registry. 2020. http://www.isrctn.com/ISRCTN89951424. Accessed 26 Aug 2020.

62. Clinical Trial of Efficacy and Safety of Sinovac's Adsorbed COVID-19 (Inactivated) Vaccine in Healthcare Professionals (PROFISCOV)-ClinicalTrials. gov. Clinicaltrials.gov. 2020. https://clinicaltrials.gov/ct2/show/NCT04 456595. Accessed 26 Aug 2020

63. A Phase III clinical trial for inactivated novel coronavirus pneumonia (COVID-19) vaccine (Vero cells)-Chictr.org [Internet]. Chictr.org. 2020. http://www.chictr.org.cn/showprojen.aspx?proj=56651. Accessed 26 Aug 2020

64. Shann F. The non-specific effects of vaccines. Arch Dis Child. 2010;95(9):662-7.

65. Mukherjee S, Subramaniam R, Chen H, Smith A, Keshava S, Shams H. Boosting efferocytosis in alveolar space using BCG vaccine to protect host against influenza pneumonia. PLoS ONE. 2017;12(7):e0180143.

66. Salem A, Nofal A, Hosny D. Treatment of common and plane warts in children with topical viable Bacillus Calmette-Guerin. Pediatr Dermatol. 2012;30(1):60-3.

67. Vasekar M, Degraff D, Joshi M. Immunotherapy in Bladder Cancer. Current Molecular Pharmacology. 2016;9(3):242-51.

68. Covián C, Retamal-Díaz A, Bueno S, Kalergis A. Could BCG vaccination induce protective trained immunity for SARS-CoV-2? Front Immunol. 2020;11:970.

69. Sharma A, Batra G, Kumar M, Mishra A, Singla R, Singh A, et al. BCG as a game-changer to prevent the infection and severity of COVID-19 pandemic? Allergol Immunopathol. 2020:48(5):507-17.

70. Miller A, Reandelar M, Fasciglione K, Roumenova V, Li Y, Otazu G. Correlation between universal BCG vaccination policy and reduced mortality for COVID-19. medRexiv. 2020.

71. Ozdemir C, Kucuksezer U, Tamay Z. Is BCG vaccination affecting the spread and severity of COVID-19? Allergy. 2020;75(7):1824-7.

72. Tomita Y, Sato R, Ikeda T, Sakagami T. BCG vaccine may generate crossreactive $T$ cells against SARS-CoV-2: in silico analyses and a hypothesis. Vaccine. 2020;38(41):6352-6. 
73. Kleinnijenhuis J, Quintin J, Preijers F, Benn C, Joosten L, Jacobs C, et al. Long-lasting effects of BCG vaccination on both heterologous Th1/Th17 responses and innate trained immunity. J Innate Immun. 2013;6(2):152-8.

74. Search of: BCG |COVID-19-List Results-ClinicalTrials.gov. Clinicaltrials.gov. 2020. https://clinicaltrials.gov/ct2/results?cond=COVID -19\&term=BCG\&cntry=\&state=\&city=\&dist=. Accessed 3 Nov 2020.

75. Venkataraman A, Yusuff M, Liebeschuetz S, Riddell A, Prendergast A. Management and outcome of Bacille Calmette-Guérin vaccine adverse reactions. Vaccine. 2015;33(41):5470-4

76. Dockrell $H$, Smith S. What have we learnt about BCG vaccination in the last 20 years? Front Immunol. 2017:8:1134

77. Mansoor N, Scriba T, de Kock M, Tameris M, Abel B, Keyser A, et al. HIV-1 infection in infants severely impairs the immune response induced by Bacille Calmette-Guérin Vaccine. J Infect Dis. 2009;199(7):982-90.

78. Satti I, Meyer J, Harris S, Thomas Z, Griffiths K, Antrobus R, et al. Safety and immunogenicity of a candidate tuberculosis vaccine MVA85A delivered by aerosol in BCG-vaccinated healthy adults: a phase 1, double-blind, randomised controlled trial. Lancet Infect Dis. 2014;14(10):939-46.
79. Jeyanathan M, Thanthrige-Don N, Afkhami S, Lai R, Damjanovic D, Zganiacz A, et al. Novel chimpanzee adenovirus-vectored respiratory mucosal tuberculosis vaccine: overcoming local anti-human adenovirus immunity for potent TB protection. Mucosal Immunol. 2015;8(6):1373-87.

80. Graham B. Rapid COVID-19 vaccine development. Science. 2020;368(6494):945-6.

81. Yip M, Leung $N$, Cheung C, Li P, Lee H, Daëron M, et al. Antibodydependent infection of human macrophages by severe acute respiratory syndrome coronavirus. Virol J. 2014;11(1):82.

82. Kam Y, Kien F, Roberts A, Cheung Y, Lamirande E, Vogel L, et al. Antibodies against trimeric $S$ glycoprotein protect hamsters against SARS-CoV challenge despite their capacity to mediate FcyRII-dependent entry into B cells in vitro. Vaccine. 2007;25(4):729-40.

\section{Publisher's Note}

Springer Nature remains neutral with regard to jurisdictional claims in published maps and institutional affiliations.
Ready to submit your research? Choose BMC and benefit from:

- fast, convenient online submission

- thorough peer review by experienced researchers in your field

- rapid publication on acceptance

- support for research data, including large and complex data types

- gold Open Access which fosters wider collaboration and increased citations

- maximum visibility for your research: over $100 \mathrm{M}$ website views per year

At BMC, research is always in progress.

Learn more biomedcentral.com/submissions 